\title{
El castigo y la destrucción de los impíos en Elena G. de White
}

CHRISTIAN VARELA ${ }^{1}$

Resumo: En los últimos años, diversos enfoques han cuestionado y argumentado contra la enseñanza tradicional del castigo y sufrimiento consciente sin fin luego de la muerte. Frente a estas controversias, cabe preguntarse en el contexto de la escatología aniquilacionista sostenida por la Iglesia Adventista del Séptimo Día cuáles fueron los principios sostenidos por su pionera Elena G. de White sobre el destino final de los impíos. El propósito de la investigación es describir, sistematizar y establecer las creencias sostenidas por ella sobre el castigo y destrucción final de los impíos. El estudio presentará brevemente la comprensión de estos temas en el movimiento millerita, los adventistas del Albany y escritores prominentes en los inicios de la Iglesia Adventista. En este contexto, se hará mención del cambio del pensamiento tradicional de Elena G. de White al condicionalista durante su experiencia religiosa temprana. Luego, se analizará su interpretación sobre el castigo y destrucción de los pecadores en El conflicto de los siglos y otras publicaciones.

Palavras-Chave: Elena G. de White; Infierno; Condicionalismo; Aniquilacionismo; Universalismo.

\section{The punishment and destruction of the wicked in Ellen G. White}

\begin{abstract}
In recent years, several approaches have questioned and argued against the traditional teaching of punishment and unending conscious suffering after death. In the face of these controversies, it is worth asking, in the context of the annihilating eschatology carried out by the Seventh-day Adventist Church, what were the principles defended by its pioneer Ellen White, about the final destiny of the wicked. The objective of the investigation is to describe, systematize and establish as beliefs it maintains regarding the punishment and final destruction of the wicked. The study will briefly present an understanding of these issues in the Millerite movement, Albany Adventists, and prominent writers at the beginning of the Adventist Church. In this context, the shift from traditional thinking by Ellen G. White to the conditionalist during her initial religious
\end{abstract}

1 Magíster en Teología por la Universidad Adventista del Plata. Actualmente, es pastor distrital de la Asociación Argentina Central. E-mail: christian.varela@adventistas.org.ar 
experience will be mentioned. Then, her interpretation of the punishment and destruction of sinners in The Great Controversy and other publications will be analyzed.

Keywords: Ellen G. White; Hell; Conditionalism; Annihilationism; Universalism.

Uno de los temas más aterradores por los siglos ha sido el sufrimiento eterno de los impíos después morir. En los últimos años, diversos enfoques, condicionalistas/ aniquilacionistas ${ }^{2}$, purgatoriales $^{3}$ y universalistas ${ }^{4}$ han cuestionado y argumentado contra la enseñanza tradicional del castigo y sufrimiento consciente sin fin luego de la muerte. Frente a estas controversias actuales, cabe preguntarse en el contexto de la escatología aniquilacionista sostenida por la Iglesia Adventista del Séptimo Día (ASOCIACIÓN MINISTERIAL DE LA ASOCIACIÓN GENERAL DE LOS ADVENTISTAS DEL SÉPTIMO DÍA, 2007, p. 409-413), ¿Cuáles fueron los principios sostenidos y promovidos por su pionera Elena G. de White sobre el destino final de los impíos? 5

Si bien se han realizado diversos estudios con respecto a su creencia sobre el estado de los muertos, ${ }^{6}$ son escasos los que se refieren a los temas a tratar. ${ }^{7}$ Por esta razón, el propósito de la investigación es describir, sistematizar y establecer los principios sostenidos por ella sobre el castigo y la destrucción final de los pecadores. El análisis comenzará presentando brevemente la comprensión de estos temas en el movimiento millerita, los adventistas del Albany y escritores referentes en los inicios de la Iglesia Adventista del Séptimo Día (IASD). En este contexto, se hará mención del cambio radical de la autora en su forma de concebir la creencia tradicional a la condicionalista durante su experiencia religiosa temprana. Luego, se analizará su interpretación a través de sus publicaciones desde un enfoque sincrónico. Sin embargo, se hará referencia de manera concisa al desarrollo de sus ideas principales expresadas en las obras Spiritual Gift volume 1 (1858), Spirit of Prophecy volume 4 (1884) y The Great Controversy, conocido en español como El conflicto de los siglos $(1888,1911)$. Sobre todo, se hará un estudio exhaustivo en este último. Finalmente, se presentarán otros conceptos complementarios de la escritora abordados en otras publicaciones que ayudarán a tener un panorama más amplio de lo enseñado por ella.

LeRoy Froom (1965) afirmó que en los primeros tiempos del movimiento adventista no hubo un interés en la naturaleza y destino del hombre. Varios de sus líderes creían en el castigo consciente sin fin de los pecadores. Sin embargo, la influencia del condicionalismo fue evidente en la predicación de algunos milleritas, los adventistas de Albany, y luego en los sabatistas que iniciarían la IASD.

\footnotetext{
2 Véase Fudge (2011); Pinnock (1992); Travis (2008); Date, Stump, Anderson (2014); Powys (2007); Date, Highfiel, (2015); Stackhouse Jr (2016).

3 Hayes (1996); Walls $(2012,2015,2016)$.

4 Jan Bonda (1998); MacDonald (2012); Talbott (2014).

5 Elena G. de White es reconocida como cofundadora de la IASD. Además, es considerada profeta de la denominación (Asociación ministerial de la Asociación General de los Adventistas del Séptimo Día, 2007, p. 246-261).

${ }^{6}$ Véase el trabajo de A. Corrêa (2008) sobre desarrollo un sobre el desarrollo de la mortalidad del alma en el pensamiento la autora entre los años 1842 a 1884. Otros estudios son enfocados en el desarrollo e integración doctrinal de la creencia del estado de los muertos de los pioneros en general, entre ellos Elena G. de White. Timm (2018); Paroschi (2017, p. 26-36); Froom (1965, p. 676-779).

7 J. Miranda Rocha (2007) realizó un estudio sobre el sufrimiento de los impíos y de Cristo citando varias declaraciones de la autora con referencias a las consecuencias de la adopción de la creencia de la inmortalidad del alma, ira de Dios y la agonía de los impíos durante el castigo divino.
} 


\title{
El castigo y destrucción de los impíos durante el adventismo millerita (1831-1844]
}

Entre las personas más influyentes del millerismo se reconoce a George Storrs. Fue el primer millerita que estudio y enseñó sobre la naturaleza mortal del hombre. En 1837 aceptó la inmortalidad condicional y la destrucción final de los impíos a través del análisis de un folleto de Henry Grew ${ }^{8}$. Storrs fue predicador metodista episcopal hasta 1840, tiempo en que reconoció que sus creencias condicionalistas no eran avaladas por su denominación. En 1841 publicó su estudio titulado An Enquiry: Are the Souls of the Wicked Immortal? In Six sermons ["Un análisis: ¿Son inmortales las almas de los impíos? En seis sermones"]. ${ }^{9}$ Este folleto se diseminó ampliamente en América y Europa. En 1842, y por la influencia de Calvin French aceptó la esperanza millerita y se abocó a la predicación de la venida de Cristo. Asimismo, fue ganando reputación por sus sermones sobre la condicionalidad de la inmortalidad en el gran movimiento religioso. Afirmó que la creencia de la inmortalidad del alma era un engaño papal y parte de los engaños de Babilonia (STORRS, 1843, p. 13).

Storrs enfrentó la oposición de algunos dirigentes, entre ellos Josiah Litch. Éste escribió The Anti-Annihilationist ["El anti aniquilacionista"] (1844), refutando las ideas de sus escritos. William Miller, también escribió un artículo en mayo de 1844 desacreditando las enseñanzas de Storrs. Él expresó abiertamente: "No puedo estar en silencio y sin discrepar de esto por más tiempo, sería un crimen contra Dios y el hombre. Por lo tanto, negamos cualquier tipo de conexión, la comunión, o simpatía con los puntos de vista del hermano Storrs, del estado intermedio, y el fin de los malvados" (1844, p. 355). La teología de Miller estaba centrada en la venida de Cristo, y este tema no le era de importancia (KNIGHT, 1993, p. 282). Él expresó en su credo número trece: "Creo que todos los impenitentes serán destruidos de la tierra, y enviados al lugar preparado para el diablo y sus ángeles" (BLISS, 1853, p. 79). Luego, en creencia diecisiete, sobre la resurrección justos e impíos, refiriéndose a estos últimos después del milenio sostuvo: "cuando los justos reciban la vida eterna, los injustos la eterna condenación” (BLISS, 1853, p. 79).

Joshua V. Himes también manifestó que fue un tema de menor importancia ante la inminencia del regreso de Jesús. Knight citó las palabras del predicador:

\begin{abstract}
Estaba ocupado con la inminencia de la Segunda Venida, estas otras opiniones me parecieron un tema secundario, y de ninguna importancia especial. Jesús estaba cerca, y en mi opinión era más importante preparar a un pueblo para su venida, que iluminarlo en estas otras preguntas. Si los hombres dormían o eran conscientes de la muerte, y si eran destruidos o sufrían eternamente por el pecado, eran cuestiones de menor importancia para mí. Dios haría lo correcto; y pronto debería saberlo todo. Mi negocio era proclamar la venida gloriosa y el reino de Cristo y prepararme a mí y a los demás para encontrarnos con el juez (KNIGHT, 1993, p. 284).
\end{abstract}

\footnotetext{
${ }^{8}$ Henry Grew (1781-1862) fue un ex pastor bautista que se destacó como un escritor prolifero con respecto a la condicionalidad de la inmortalidad. Para mayores detalles biográficos véase Froom (1965, p. 300-305).

9 Véase también Storrs (1844a; 1844b).
} 
A pesar de esto, Charles Fitch (1805-1844), pastor presbiteriano, se dedicó a profundizar estas enseñanzas, siendo el primero entre los predicadores milleritas en aceptar las enseñanzas de Storrs (KNIGHT, 2007, p. 72-73). Él le expreso lo siguiente:

Apreciado hermano Storrs: como lleva mucho tiempo luchando en solitario las batallas del Señor, en lo referente al tema del estado de los muertos y del destino final de los malvados, le escribo esto para decirle que, después de mucha reflexión y oración, y de una profunda convicción de mi deber para con Dios, estoy dispuesto a ponerme de su parte (STORRS, 1850, p. 110).

Durante este periodo se vislumbran dudas y rechazos con respecto al condicionalismo y la aniquilación de los pecadores. James White recordaba que esos temas fueron de gran agitación en el movimiento que esperaba el regreso de Jesús (WHITE, 1868, p. 154-155). No obstante, la influencia de Storrs repercutió positivamente en muchos creyentes del adventismo millerita luego de la fragmentación tras el chasco ocurrido el 22 de octubre de 1844.

\section{El castigo y destrucción de los impíos para los adventistas de Albany}

La Conferencia de Albany (Nueva York, 29 de abril de 1845) fue con respecto al condicionalismo y aniquilacionismo. Allí, algunos adventistas que profesaban el regreso de Jesús después del chasco tomaron diez puntos doctrinales claves relacionados al advenimiento y la salvación. Entre ellos, acentuaron que los impíos recibirán su castigo luego del regreso de Cristo ${ }^{10}$. Entre esta conferencia y la muerte de Miller (1849), el adventismo tradicional de Albany se fragmentó entre los que aceptaron el condicionalismo y aniquilacionismo y los que no ${ }^{11}$. Knight afirmó al respecto lo siguiente: "La insensibilidad de los editores de Advent Herald al creciente sentimiento condicionalista preparó progresivamente el escenario para el cisma en las filas de Albany a fines de la década de 1840 y principios de la década de 1850" (1993, p. 285).

Entre los partidarios de la naturaleza mortal del hombre se destacó la Iglesia Adventista Cristiana ${ }^{12}$. Escritores de esta denominación manifestaron su posición condicionalista sobre la naturaleza del hombre y aniquilacionista sobre el destino final de los pecadores a través de libros, folletos y artículos de periódicos ${ }^{13}$.

\footnotetext{
10 Arthur Whitefield Spalding abordando lo sucedido en Albany sobre el tema en cuestión declara: "Second, the doctrine of unconsciousness in death and immortality received only through Christ the Life-giver. At that time probably three fourths of Adventists believed in the conscious state of the dead, but the opposite doctrine was gaining. The Albany Conference, seeking to bind together all factions, dodged this question by a vague declaration that the righteous dead did not receive their reward until Christ comes. The question, however, was destined in later years to divide the Adventists irrevocably, the then dominant party who believed in the conscious state of the dead disappearing altogether" (1949, p. 142).

11 Para mayores detalles veáse a Knight (1993, p. 283-293).

12 Richard W. Schwarz y Floyd Greenleaf destacaron que Joshua V. Himes formó parte de esta iglesia: "In 1862 Himes broke with his old colleagues by accepting the doctrine of 'soul sleep' and eventually joined this group to form the Advent Christian Church, the largest nonsabbatarian remnant of Adventism" (SCHWARZ; GREENLEAF, 1979, p. 57).

13 Cf. Advent Harbinger and Bible Advocate, Advent Watchman y World's Crisis.
} 


\section{La destrucción de los impíos para los pioneros adventistas del Séptimo Día}

Aunque algunos de los pioneros sabatistas creían en el castigo consciente eterno, tras los diferentes estudios llegaron a las conclusiones condicionalista y aniquilacionista. Hasta 1850, los pioneros realizaron pocas referencias a estos temas (TIMM, 2018, p. 96).

Alberto R. Timm (2018, p. 53-54) destaca que entre los años 1844 y 1847, los pioneros estudiaron las Escrituras estableciendo cinco creencias básicas que integrarían un sistema doctrinal distintivo. Estos pilares fueron: (1) la segunda venida de Cristo en forma personal, visible y premilenial; (2) el ministerio sacerdotal de Cristo en el Santuario Celestial, sobre todo lo ocurrido el 22 de octubre de 1844; (3) la inmortalidad condicional del alma y la aniquilación final de los impíos; (4) la perpetuidad de la ley de Dios, incluyendo la observancia del sábado; (5) y la manifestación del don de profecía en Elena G. de White. Estos adventistas encontraron en las Escrituras la base para sostener estas verdades. Asimismo, Timm destaca que ellos vincularon la doctrina de la inmortalidad condicional al Santuario celestial y a los mensajes de los tres ángeles de la siguiente manera:

\footnotetext{
Al santuario a través del apoyo que la misma proveyó al concepto de un juicio previo al advenimiento enfocado en los muertos. La misma doctrina estaba conectada a los mensajes de los tres ángeles mediante la idea de que la inmortalidad del alma era una de las mayores falsificaciones de la bestia de la verdad de Dios mencionada en Apocalipsis 14:9-11 (TIMM, 2018, p. 97-98).
}

Varios pioneros escribieron sobre la naturaleza del hombre y el destino final de los impíos. Timm afirma que frente al auge del espiritismo iniciado por las hermanas Fox en Nueva York (1848), los adventistas sabatistas declararon que era un engaño satánico a través de sus escritos. Ellos sostuvieron basados en la Biblia la verdadera condición sobre estado de los muertos entre los años de 1850 a 1860 (TIMM, 2018, p. 186-188). La misma Elena G. de White afirmó en 1849 que los golpecitos escuchado por las hermanas era obra de Satanás (WHITE, 1849).

Uno de los líderes más influyentes acerca del condicionalismo en la naciente iglesia fue Joseph Bates. Según LeRoy Froom (1965, p. 675-676; cf. TIMM, 2018, p. 96), él lo aprendió de la congregación Conexión Cristiana ${ }^{14}$, a la cual también pertenecía James White. El antiguo capitán escribió y expuso sus ideas condicionalistas en Second Advent Waymarks and High Heaps (BATES, 1847) y se opuso al espiritismo de su tiempo a través del libro The Opening Heavens (BATES, 1846). James White también lo hizo en su escrito A Word to the Little Flock $(1847 ; 1853)$. Según la Enciclopedia Adventista del Séptimo Día (1995), Roswell F. Cottrell fue el primer líder adventista del séptimo día que publicó en la Review and Herald una de las primeras afirmaciones claras sobre el estado inconsciente de los muertos (1853). Merritt Cornell realizó una importante recopilación de citas de autores cristianos de todos los tiempos para demostrar que la creencia de la inmortalidad condicional no era una creencia sostenida solamente por los adventistas (1858). John N. Loughborough, igualmente destacó que la enseñanza de la inmortalidad del alma tuvo sus orígenes en las creencias paganas $(1855,1859)$. Además, testificó sobre su recibimiento de la creencia condicionalista y aniquilacionista propuesta por Storrs:

${ }^{14}$ Aunque esta creencia no fue distintiva en la congregación. 
A mí me trajo alegría por el alivio que trajo a mi mente torturada durante años al escuchar sobre el "infierno sin fin" que me auguraban en las predicaciones si yo no era bueno. Deseé muchas veces que me dijeran cómo ser bueno, en lugar de decirme tanto acerca de los terrores del infierno (LOUGHBOROUGH, 2015, p. 460).

Otros estudios importantes fueron realizados por D. P. Halll (1854a; 1854b) ${ }^{15}$, J. N. Andrews $(1854 ; 1855 ; 1856 ; 1876 ; 1889 ; 1890)$, Canright (1863a; 1863b; 1871), B. F. Snook (1863), A. T. Jones (1890), E. Waggoner (1857; 1859; 1870) y U. Smith (1856; 1884a; 1884b; 1897).

En 1872, Uriah Smith escribió “una declaración de los principios fundamentales”. Allí delineó las principales creencias de los Adventistas del Séptimo Día. En los principios 19 y 20 afirmó que la persona se encuentra en un estado de entera inconsciencia. En el 23 destacó que Satanás será “finalmente destruido" luego del milenio. En el 24, expresó:

\begin{abstract}
Al final de mil años, el Señor desciende con su pueblo y la Nueva Jerusalén, Ap. 21: 2, los muertos inicuos son resucitados y suben a la superficie de la tierra aún no renovada, y se reúnen alrededor de la ciudad, el campamento de los santos, Ap. 20: 9 y el fuego desciende de Dios del cielo y los devora. Luego se consumen raíz y rama, Mal. 4.1, convirtiéndose en como si no hubieran sido. Abd. 15, 16. En esta destrucción eterna de la presencia del Señor, 2 Tes. 1: 9, los impíos se encuentran con el castigo eterno amenazado contra ellos. Mate. 25:46. Esta es la perdición de los hombres impíos, el fuego que los consume es el fuego para el cual "el cielo y la tierra que ahora están guardados, que derretirá incluso los elementos con su intensidad, y purgará la tierra de las manchas más profundas. de la maldición del pecado." 2 Pedro 3: 7-12 (SMITH, 1872, p. 14).
\end{abstract}

En este contexto doctrinal, Smith, en 1862 había declarado que "el sueño de los muertos" y la "destrucción de los impíos" eran pruebas de comunión del cuerpo Adventista del Séptimo Día (1862, p. 53). La IASD desde sus inicios comprendió y sostuvo que el condicionalismo y el aniquilacionismo poseía fundamento bíblico. La enseñanza tradicional era un engaño. Por tal motivo, estas creencias fueron parte de su mensaje distintivo.

\title{
El castigo y destrucción de los impíos en los escritos de Elena G. de White
}

Elena G. de White en sus escritos sostuvo el condicionalismo y aniquilacionismo. Sin embargo, estas no fueron sus creencias iniciales. Ella testificó sobre su traumática experiencia religiosa con respecto al castigo de los impíos consciente, tortuoso y eterno en el infierno. No obstante, al estudiar las Escrituras, rechazó la doctrina tradicional. A continuación, se realizará un estudio teológico de la comprensión del castigo y destrucción de los impíos en el pensamiento de la autora. Por esta razón, el enfoque de la exploración será descriptivo, sistemático y sincrónico más que diacrónico. Al analizar las fuentes, no se halló un cambio radical en sus escritos iniciales. Sí se percibe una ampliación de conceptos que brevemente se hará referencia en los libros Spi-

\footnotetext{
15 Según Malcolm Bull y Keith Lockhart, "D. P. Hall was the first Seventh-day Adventist to give a systematic account of the doctrine of humanity in the light of this apocalyptic orientation” (2007, p. 89).
} 
ritual Gifts volume 1 (1858) y Spirit of Prophecy volume 4 (1884), escritos antecesores de la obra The Great Controversy, conocido en español como El conflicto de los siglos $(1888,1911)$. Luego, se ampliarán sus conceptos a través del análisis de otras publicaciones.

\section{La doctrina del castigo eterno en su experiencia temprana}

Elena G. de White relató en su autobiografía los sucesos que marcaron sus experiencias tempranas con respecto a las ideas del castigo en el infierno $(1855 ; 1860 ; 1915)^{16}$. La familia White pertenecía a la Iglesia Metodista Episcopal. En marzo de 1840, Elena asistió a unas conferencias en Portland brindadas por William Miller. Allí fue convencida del pronto regreso de Jesús. Durante la segunda serie de conferencias de Miller en junio de 1842 reforzó esta convicción. Estos encuentros le despertaron la inquietud sobre la santificación, lo que la llevó a cuestionarse: “¿Qué debo hacer para ser salva?" (WHITE, 2013. p. 31). Frente a este interrogante, ella manifestó que tuvo una angustia mental por las ideas que tenía sobre la justicia, la misericordia y el amor de Dios. Tenía miedo de perderse y vivir la eternidad en el infierno que ardía eternamente. Había escuchado horribles descripciones de este lugar, donde Satanás y sus demonios gobernaban las almas y los torturaba por la eternidad. A todo esto, se presentaba a Dios como un tirano, lo que le causaba "mucha perplejidad y dolor" (WHITE, 2013, p. 33). Como metodista había sido adoctrinada con la creencia tradicional. Por esta razón expresaba este temor al castigo por causa de su concepto de santidad y relación con Dios. Luego, tras una clara exposición del carácter divino, comprendió que no era un tirano, ella lo amo profundamente y cambió su manera de interpretar la salvación y justicia divina.

Otro incidente que marcó su comprensión sobre la inmortalidad del alma y el destino de los impíos fue una conversación que sostuvo con su madre acerca del tema. Eunice hablaba con una amiga sobre un discurso que había oído "acerca de que el alma no es inmortal por naturaleza" (WHITE, 2013, p. 49). En el dialogo citaron los versículos bíblicos como Ezequiel 18:4; Eclesiastés 9:5, Timoteo 6:15-16 y Romanos 2:6-7. Elena afirmó que escuchó "estas nuevas ideas con intenso y doloroso interés" (WHITE, 2013, p. 49). Luego, a solas con ella, le preguntó si creía que el alma no era inmortal, a lo que su progenitora le respondió que a su parecer temía que hubiesen "estado errados en aquella cuestión, lo mismo que en varias otras" (WHITE, 2013, p. 41). De esta manera, ella argumentó que "la Biblia no contiene prueba alguna de que haya un infierno eterno. Si existiese un lugar tal, el Libro sagrado lo mencionaría" (WHITE, 2013, p. 50).

Luego de un tiempo de reflexión, ella escuchó una predicación en la cual se expuso esta verdad y la aceptó inmediatamente (WHITE, 2013, p. 50). De esta manera, expresó que pudo conciliar la idea de la recompensa o castigo con la doctrina de la resurrección y el juicio futuro (WHITE, 2013, p. 50). Así, aceptó el condicionalismo y la anhelada resurrección de los muertos, concluyendo lo siguiente: "entonces me di cuenta de la falacia de nuestro primitivo criterio sobre el asunto" (WHITE, 2013, p. 50). Además, habló en otro escrito sobre esta experiencia temprana:

La angustia mental por la que pasé en este momento fue muy grande. Creía en un infierno eternamente ardiente; $y$ al pensar en el miserable estado del pecador ante Dios, estaba profunda-

16 Los sucesos se encuentran relatados en sus obras Testimonies for the Church volume 1 (1855), My Christian Experience, Views, and Labors, in Connection with The Rise and Progress of the Third Angel's Message (1860), y finalmente se compiló en Life Sketches of Ellen G. White (1915). Esta última publicación se encuentra disponible en español bajo el titulo Notas biográficas de Elena G. de White (2013). El autor utilizará esta como referencia para la exposición del pensamiento la autora. 
mente desesperada. Temía estar perdida y vivir toda la eternidad sufriendo una muerte viviente. Pero aprendí mejor que esto. Aprendí que tenía un Dios que es demasiado misericordioso para perpetuar durante toda la eternidad la vida de los seres que creó para su gloria, pero que, en lugar de aceptar al Salvador, había muerto impenitente, implacable y sin salvación. Aprendí que los impíos serán consumidos como rastrojo, y que serán como cenizas bajo nuestros pies en la tierra nueva; serán como si no hubieran sido. No hay infierno eternamente ardiente; no hay cuerpos vivos que sufran tormentos eternos (WHITE, 1908, p. 7).

\section{El castigo y destrucción de los impíos en Spiritual Gifts y Spirit of Prophecy}

Antes de estudiar lo expuesto en el libro The Great Controversy, llamado en español El conflicto de los siglos, se realizará una breve mención a sus obras antecesoras. Su origen se debió a la llamada visión del "gran conflicto" que recibió Elena G. de White el 14 de marzo de 1858. Luego, en septiembre de 1858, ella publicó el libro Spiritual Gifts volume 1. Casi treinta años más tarde, en 1884 publicó Spirit of Prophecy Volume 4: The Great Controversy. Allí amplió lo expuesto anteriormente. Finalmente, en 1888, fue publicado The Great Controversy, el cual fue revisado en 1911.

En lo que respecta al tema en estudio, Elena G. de White, sentó las bases del condicionalismo y aniquilacionismo en Spiritual Gifts (1858) ${ }^{17}$. En el capítulo 19 ella expuso que la muerte no es vida eterna en miseria. Expresó su asombro por el éxito de Satanás al engañar a las personas con la creencia de un tormento continuo (p. 114). Aseveró que esta enseñanza era una "herejía popular" (p. 116). Además, esta doctrina tiene su fundamento en la mentira expresada por Satanás en el Edén al afirmar "no moriréis". Así, él indujo a las personas a "creer que el pecador habrá de vivir en continuo tormento eterno" (WHITE, 1858, p. 113-114). De esta manera, el engaño está sujeto a la creencia de la inmortalidad del alma. Al mismo tiempo, sentó las bases contra el universalismo (p. 115) que luego desarrollaría en Spirit of Prophecy. También presentó las graves consecuencias que generaron estas creencias en las personas (p. 116), entre ellas, desvirtúa el carácter de Dios (p. 115). Por último, destacó la importancia de tener un fundamento seguro en la Palabra de Dios para evitar el engaño (p. 116-118) ${ }^{18}$. En el capítulo 30 presentó al "espiritismo" como el gran engaño de Satanás. Declaró que él tiene el poder de personificar a los fallecidos que descansan en Jesús como también a incrédulos como Thomas Paine. En el capítulo 42 presentó el castigo y la destrucción de los impíos luego del milenio. Algunos puntos básicos que planteó son los siguientes: (1) El fuego proviene de Dios (p. 217); (2) Los impíos son castigados de acuerdo con sus obras. Algunos son consumidos rápidamente mientras que otros no (p. 218); (3) Satanás y sus ángeles sufrirán por mayor tiempo (p. 218); (4) Satanás sufrirá por los pecados propios, los pecados de los redimidos y por los de las almas perdidas (p. 218); (5) Todos los impíos serán consumidos, y así se podrá satisfacer la justicia de Dios (p. 218); (6) Esta destrucción será la muerte eterna, “jamás van a tener resurrección” (p. 218). Anteriormente había afirmado que será “una muerte sin esperanza de resurrección” (p. 114); (7) El

\footnotetext{
17 El libro Spiritual Gifts (1858) se encuentra en la tercera sección de la obra Primeros escritos (2017).

18 Ella había escrito en 1854 lo siguiente: "Vi que los santos deben obtener un conocimiento profundo de la verdad presente, que tendrán que recibir de las Escrituras. Ellos deben estar al tanto respecto al estado de los muertos; porque los espíritus de demonios se les aparecerán incluso a ellos, diciendo ser amigos queridos y familiares, declarando que se han cambiado el día de reposo, así como otras doctrinas de las Escrituras" (WHITE, 1854, p. 6).
} 
fuego que consumió a los impíos también purificará la tierra (p. 218); (8) Todo el universo de Dios estará limpio y terminará para siempre el gran conflicto (p. 218).

En Spirit of Prophecy Volume 4 (1884), ella amplió estos conceptos. Allí presentó el tema del condicionalismo en dos capítulos continuos: "El primer gran engaño" (cap. 28) y "Espiritismo" (cap. 29). En esta obra realizó importantes aportes. Igualmente, en el último capítulo amplia en detalles el fin de los impíos (cap. 37). Estos desarrollos serán analizados en detalle a continuación, al estudiar lo expresado en El conflicto de los siglos. No se presentan mayores cambios o agregados significativos entre lo que escribió en 1884, 1888 y 1911.

\section{El castigo y la destrucción de los impíos en El conflicto de los siglos ${ }^{19}$}

En esta obra que llevó casi seis décadas de elaboración, enfatizó la importancia de la fidelidad para alcanzar la resurrección de los santos y la inmortalidad en Cristo Jesús. Por otro lado, a Satanás, sus ángeles y a los impíos les espera la completa y definitiva destrucción tras la batalla escatológica post milenial.

\section{El castigo consciente y sin fin es un engaño de la Babilonia espiritual}

Ella expresó que la enseñanza tradicional es un engaño que se opone a lo expuesto en las Escrituras. Exclamó: “¡Y qué repulsiva la creencia de que apenas exhalado el último suspiro, el alma del impenitente es arrojada a las llamas del infierno!” (WHITE, 2015, p. 601). También afirmó que estas ideas provienen de la iglesia romana, "es una de las falsas doctrinas que constituyen el vino de las abominaciones de Babilonia, del cual ella da de beber a todas las naciones" (WHITE, 2015, p. 591).

\section{Las nefastas consecuencias de la creencia del castigo consciente $y$ sin fin}

Ella afirmó que "muchos han sido arrastrados a la locura por causa de este horroroso pensamiento" (WHITE, 2015, p. 601). En otro escrito también presentó una relación estrecha entre la falsa enseñanza de un castigo consciente y sin fin con las enfermedades mentales. Por esta razón, afirmó en otras publicaciones: "Hay también doctrinas erróneas como la de un infierno que arde eternamente y el tormento sin fin de los impíos, que, al presentar ideas exageradas y distorsionadas del carácter de Dios, han producido el mismo resultado [enfermedades] en las mentes sensibles" (WHITE, 1882, p. 444) ${ }^{20}$.

Asimismo, afirmó que muchos de "los pacientes internados en los asilos con enfermos mentales fueron llevados allí por experiencias similares" a las de ella en su experiencia temprana (WHITE, 1885, p. 25-26). Esto se debía a que "escuchaban las descripciones del infierno enseñado por la ortodoxia" (WHITE, 1885, p. 25). Ante estas experiencias, destacó que para aquellas personas "el terrible cuadro estaba siempre delante de ellos, hasta que la realidad se perdió en la imaginación, y sólo podían ver las llamas ondulantes de un infierno fabuloso y podían oír solo los agudos gritos de los condenados" (WHITE, 1885, p. 26).

\footnotetext{
19 Para el presente estudio se tomará como referencia la edición en español publicada por Asociación Casa Editora Sudamericana, 2015.

20 El libro Testimonies for the Church volume 1 compila panfletos de Elena G. de White de 1855.
} 
Por medio de esta creencia, Satanás "reviste con sus propios atributos al Creador y Bienhechor de la humanidad" (WHITE, 2015, p. 589). Esto induce a los creyentes a "malinterpretar las enérgicas expresiones de las Escrituras y dar al lenguaje bíblico un tinte de amargura y malignidad que es propio de él, Satanás, pero no de nuestro Creador" (WHITE, 2015, p. 590-591).

También ha hecho que muchos desautoricen la inspiración de la Biblia. Por eso, "han hecho que miles y hasta millones de escépticos e incrédulos" (WHITE, 2015, p. 591). En conclusión, la falsa creencia ha generado graves consecuencias en la vida espiritual de la humanidad por siglos.

\section{La enseñanza tradicional se opone a los principios de amor y justicia}

Algunos teólogos de su tiempo afirmaban que Dios y los salvos mirarían sin ningún dolor la tortura de los condenados por la eternidad. Ella reprodujo las expresiones del sermón de Jonathan Edwards predicado en abril de 1739, The Eternity of Hell Torments, que cita:

El espectáculo de los tormentos del infierno aumentará para siempre la dicha de los santos. Cuando vean a otros seres de la misma naturaleza que ellos y que nacieron en las mismas circunstancias, cuando los vean sumidos en semejante desdicha, mientras que ellos estén en tan diferente situación, sentirán en mayor grado el goce de su felicidad (EDWARDS, 1739, online) $)^{21}$.

Al respecto de esta idea manifestó:

¿Qué ganaría Dios con que creyéramos que él se goza en contemplar los tormentos eternos, que se deleita en oír los gemidos, los gritos de dolor y las imprecaciones de las criaturas a quienes mantiene sufriendo en las llamas del infierno? ¿Pueden acaso esas horrendas disonancias ser música para los oídos de Aquel que es amor infinito?” (WHITE, 2015, p. 591).

Por esta razón exclamó: “¡Oh, qué horrible blasfemia! ¡Como si el odio que Dios tiene al pecado fuese motivo para eternizar el pecado!” (WHITE, 2015, p. 591). Por eso concluye que la destrucción de los impíos es un acto de misericordia (2015, p. 598).

\section{Otro engaño de Satanás: El renacido universalismo}

Ella vio que "muchos a quienes les repugna la doctrina del tormento eterno se lanzan al error opuesto" (WHITE, 2015, p. 592), refiriéndose a la salvación universal de los impíos. Destacó que esta idea también distorsiona el carácter divino, ya que se pasa "por alto totalmente la justicia de Dios y las advertencias de su Palabra, para presentarlo lleno de misericordia, de manera que finalmente nadie perezca, sino que todos, los santos y pecadores, se salven en su reino" (WHITE, 2015, p. 592). Ella citó a un predicador universalista que realizó el sepelio de un joven irreligioso. Él afirmó que este joven, al igual que Amnón (hijo del rey David) se encontraba en la gloria. El predicador expresó lo siguiente:

\footnotetext{
${ }^{21}$ Citado textualmente en El conflicto de los siglos (2015, p. 590).
} 


\begin{abstract}
Porque podía con su ojo de profeta echar una mirada hacia el glorioso estado, ver a su hijo muy alejado de todas las tentaciones, libertado y purificado de la esclavitud y corrupciones del pecado, y, después de haber sido suficientemente santificado e iluminado, admitido a la asamblea de espíritus superiores y dichosos. Su solo consuelo consistía en que su hijo amado al ser recogido del presente estado de pecado y padecimiento había ido adonde el soplo sublime del Espíritu Santo sería derramado sobre su alma obscurecida; adonde su espíritu se desarrollaría con la sabiduría del cielo y con los dulces transportes del amor eterno, a fin de ser así preparado para gozar con una naturaleza santificada del descanso y de las glorias de la herencia eterna (WHITE, 2015, p. 593).
\end{abstract}

Ante estas palabras ella expresó su conclusión: “ ¿Y de dónde saca sus conclusiones este falseador de las Sagradas Escrituras?” (WHITE, 2015, p. 594). Sigue afirmando: “Fábula amena, por cierto, muy apropiada para satisfacer el corazón carnal! ¡Es la doctrina del mismo Satanás y produce el efecto que él desea! ¿Es entonces de extrañar que con tales enseñanzas la iniquidad abunde?" (WHITE, 2015, p. 594). De esta manera, expuso varios argumentos teológicos y bíblicos como "evidencias contundentes" de la Palabra de Dios que Él "castigará a los transgresores de su ley" (WHITE, 2015, p. 595).

En 1858 ya había expresado su oposición al universalismo que resurgía en su tiempo. En Spirit of Prophecy y El conflicto, amplia en gran manera las ideas imperantes de estas falsas enseñanzas, aclarando con múltiples referencias bíblicas el rechazo de esta.

\title{
La destrucción de los impíos evidenciará la justicia y misericordia divina
}

La autora afirmó que el fuego final evidenciará la justicia y misericordia divina ante todo el universo (WHITE, 2015, p. 599). Por medio de este acto se evidenciará que es "imposible salvar al pecador en sus pecados, lo priva de la existencia que sus transgresiones habían perdido, de la que se ha demostrado indigno" (WHITE, 2015, p. 600). Con referencia a los opresores de los santos y opositores de Dios de los todos los siglos, ella expresó que "Dios permite que los malvados prosperen y manifiesten su enemistad contra él, para que cuando hayan llenado la medida de su iniquidad, todos puedan ver la justicia y la misericordia de Dios en la completa destrucción de aquéllos" (WHITE, 2015, p. 52).

\section{La destrucción final de Satanás y los impíos}

Luego del milenio, Satanás y sus ángeles serán sueltos del abismo, y los impíos serán resucitados. Ella afirmó que "no hay nadie que defienda la causa de ellos; no tienen excusa; y se pronuncia contra ellos la sentencia de muerte eterna" (WHITE, 2015, p. 726). Claramente define esta muerte como la segunda. De esta manera, afirmó que "destruirá a todos los impíos. Así el gran plan de redención alcanzará su cumplimiento en la extirpación final del pecado y la liberación de todos los que estuvieron dispuestos a renunciar al mal" (WHITE, 2015, p. 539).

Al describir las escenas finales de los impíos en la batalla contra la Nueva Jerusalén, escribe lo siguiente: 
Dios hace descender fuego del cielo. La tierra está quebrantada. Salen a relucir las armas escondidas en sus profundidades. Llamas devoradoras se escapan por todas partes de grietas amenazantes. Hasta las rocas están ardiendo. Ha llegado el día que arderá como horno. Los elementos se disuelven con calor abrasador, la tierra también y las obras que hay en ella están abrasadas (Malaquías 4:2; 2 Pedro 3:10). La superficie de la tierra parece una masa fundida un inmenso lago de fuego hirviente. Es la hora del juicio y perdición de los hombres impíos, "es día de venganza de Jehová, año de retribuciones en el pleito de Sion" (WHITE, 2015, p. 731).

El castigo y la destrucción final de los impíos será diferente para cada uno en "duración e intensidad" según hayan sido sus obras, pero afirma que "finalmente terminará en la segunda muerte" (WHITE, 2015, p. 600). Por esta razón expresó que "algunos son destruidos como en un momento, mientras otros sufren muchos días. Todos son castigados "conforme a sus hechos" (WHITE, 2015, p. 731).

Sobre el castigo y destrucción final del Satanás expresó lo siguiente:

Habiendo sido cargados sobre Satanás los pecados de los justos, tiene éste que sufrir no sólo por su propia rebelión, sino también por todos los pecados que hizo cometer al pueblo de Dios. Su castigo debe ser mucho mayor que el de aquellos a quienes engañó. Después de haber perecido todos los que cayeron por sus seducciones, el diablo tiene que seguir viviendo y sufriendo. En las llamas purificadoras, quedan por fin destruidos los impíos, raíz y rama, -Satanás la raíz, sus secuaces las ramas. La penalidad completa de la ley ha sido aplicada; las exigencias de la justicia han sido satisfechas; y el cielo y la tierra al contemplarlo, proclaman la justicia de Jehová (WHITE, 2015, p. 731) 22.

Para explicar la aniquilación de los impíos ella hizo uso de varios textos bíblicos; Isaías 9: 5; 34: 2; Salmo 11: 6, Malaquías 4:1-2; e 2 Pedro 3:10. Ante la destrucción final de los impíos y la purificación de la tierra describió que "los justos vivían seguros en la ciudad santa. La segunda muerte no tiene poder sobre los que tuvieron parte en la primera resurrección. Mientras Dios es para los impíos un fuego devorador, es para su pueblo un sol y un escudo" (WHITE, 2015, p. 732).

El fuego exterminará a Satanás, todo pecado y pecador (2015, p. 475).$^{23}$ Ella aseveró contraponiendo la enseñanza tradicional, que no habrá "almas perdidas que blasfemen a Dios mientras se retuercen en tormentos sin fin, ni seres infortunados que desde el infierno unan sus chillidos de espanto a los himnos de los elegidos" (WHITE, 2015, p. 600). Así, el fuego purificará la tierra, eliminando "todo rastro de la maldición. Ningún infierno que arda eternamente recordará a los redimidos las terribles consecuencias del pecado" (WHITE, 2015, p. 732).

En conclusión, El conflicto de los siglos es la exposición más clara de la autora en la que presentó las creencias condicionalista y aniquilacionista en el contexto de la naturaleza del castigo y destrucción final de Satanás y los impíos. Además, se opuso a las enseñanzas tradicional y universalista. Enfatizó su perspectiva escatológica en una teodicea que coloca la justicia y la misericordia divina como centro de la escatología final de los pecadores.

\footnotetext{
22 En 1890, al publicar Patriarcas y profetas expresó esta idea la idea tomando la tipología del Día de Expiación (1890, p. 358; 1985, p. 373)

23 Es una completa aniquilación, ya que "destruirá completamente de modo que resulten como si no hubiesen existido. Entonces la quedará satisfecha la justicia de Dios. Formó al hombre del polvo de la tierra, y los desobedientes e impíos serán consumidos por el fuego y volverán de nuevo al polvo" (WHITE, 1927, p. 222). Véase también White (1906; 1991, p. 25).
} 


\section{Otros pensamientos sobre el castigo y la destrucción de los impíos}

En este contexto de lo expuesto sobre el castigo y destrucción final de los pecadores es necesario destacar otros pensamientos de la autora para un panorama más general.

\section{La victoria de Cristo y la destrucción de Satanás}

Jesús, durante su ministerio terrenal trabajó para salvar a las personas de la destrucción (2016b, p. 242). La futura destrucción del pecador y Satanás ocurrirá gracias a la muerte de Cristo en la cruz $(2014$, p. $713 ; 1985$, p. 58). Su sacrificio fue realizado "para salvar al mundo de la destrucción" (1988a, p. 288). ${ }^{24}$ De esta manera, su victoria sobre Satanás aseguró su "destrucción eterna" (1999, p. 158). Este triunfo fue el cumplimiento de la profecía edénica de Genesis 3:15, la cual señalaba su "derrota y destrucción final" (1985, p. 42).

\section{La futura destrucción, consagración y misión}

Entendiendo que el fin último del pecador será su destrucción durante el regreso de Jesús y después del milenio. En reiteradas ocasiones enfatizó la necesidad de alcanzar la vida eterna antes que la "eterna destrucción" (WHITE, 1979, p. 327). Ella destacó: "Ha llegado el tiempo cuando toda persona debiera comprender que tiene un alma que salvar o perder, un cielo que ganar y un infierno que evitar" (1991, p. 54). Esta es una expresión muy común con la cual desea instar a sus lectores a la consagración plena de todo creyente (1995, p. 392; 1992, p. 53-54; 1982, p. 116; 1991, p. 184). También la destrucción final debería llevar a los cristianos al compromiso misionero de proclamar la salvación y rescatar a los pecadores de estas trágicas consecuencias (WHITE, 2014, p. $410 ; 1999$, p. $24 ; 1982$, p. $285 ; 1979$, p. 171, 243; 1985, p. 93; 1976, p. 98).

\section{¿Quiénes serán atormentados y destruidos?}

A través de sus escritos presentó quienes serán destruidos. Entre ellos se encontrarán "los enemigos de la justicia” (1985, p. 293), los que rechacen la influencia del Espíritu Santo (1985, p. 336-337, 376), los transgresores de la ley de Dios (1985, p. 354-355, 529), los enemigos de Dios (1985, p. 517), hijos sin disciplina ni preparación para el reino (2016b, p.86), aquellos que no reprenden el pecado dentro del pueblo del Dios y contemporizan con el mal (2016b, p. 369). También serán consumidos aquellos que no venzan sus defectos de carácter por medio del Espíritu Santo (2016c, p. 237), los amantes de las riquezas (2016c, p. 543), los que son borrados del libro de la vida (1880, p. 229) y "los que no reciban el mensaje de amonestación y purifiquen sus almas obedeciendo a la verdad y siendo obedientes a las leyes de Dios" (1878, p. 1) En conclusión, ella afirmó que serían aniquilados "los impíos de toda la tierra" (1985, p. 101). Además, ella afirmó que antes de la destrucción, los pecadores sufrirán un atormento espiritual y mental por la culpa de sus propios pecados (1988b, p. 493; 2014, p. 195).

${ }^{24}$ Para más detalles véase Rocha (2007, p. 48-49). 


\title{
Tipologías de destrucción
}

Ella también realizó alusiones a varias destrucciones de la historia bíblica para referirse como tipos de la destrucción final. Entre ellas destacó la destrucción diluviana (2016a, p. 679), Sodoma y Gomorra (2016, p. 679; 1985, p. 162) y de Jerusalén (2015, p. 41; 2014, p. 581-582; 2017, p. 112). Además, comparó la translación de Enoc antes del diluvio con la de los santos "antes de la destrucción por el fuego" (1985, p. 77). Finalmente, ella comprendió que los juicios divinos de la historia bíblica fueron representaciones del juicio final sobre los impíos.

\section{La forma de la destrucción final}

Ella afirmó la manera en que los impíos serán destruidos y la tierra purificada. De esta manera, Dios protegerá a los suyos como lo hizo con los santos de la antigüedad en medio de la destrucción:

\begin{abstract}
Cuando se unan los rayos del cielo con el fuego de la tierra, las montañas arderán como un horno, y arrojarán espantosos torrentes de lava, que cubrirán jardines y campos, aldeas y ciudades. Masas incandescentes fundidas arrojadas en los ríos harán hervir las aguas, arrojarán con indescriptible violencia macizas rocas cuyos fragmentos se esparcirán por la tierra. Los ríos se secarán. La tierra se conmoverá; por doquiera habrá espantosos terremotos y erupciones. Así destruirá Dios a los impíos de la tierra. Pero los justos serán protegidos en medio de estas conmociones, como lo fue Noé en el arca. Dios será su refugio y tendrán confianza bajo sus alas protectoras (WHITE, 1985, p. 101).
\end{abstract}

De esta forma, las acciones terrestres tendrán un protagonismo importante que complementarán el fuego salido por Dios (Ap 20:9).

\section{Consideraciones finales}

Los pioneros Adventistas del Séptimo Día al sistematizar sus doctrinas, comprendieron que el condicionalismo y aniquilacionismo integraban parte de la verdad presente que debían proclamar. Elena G. de White fue una pionera de su tiempo al describir el verdadero estado de los muertos y la destrucción de los impíos en un contexto en el que primaba el tradicionalismo, y resurgían el espiritismo y el universalismo. Si bien tuvo una experiencia trágica en su práctica religiosa temprana, fue cambiada al aceptar verdad de las Escrituras. Ella organizó la antropología y escatología en el marco teológico del gran conflicto cósmico desde sus primeras referencias en 1858. Declaró las consecuencias nefastas de la creencia y predicación del engaño tradicional del sufrimiento eterno de los pecadores. Condenó el renacido universalismo como otro engaño de Satanás. Ella comprendió que la destrucción final del diablo y los impíos armoniza con la justicia y misericordia del Creador.

La autora confirmó los fundamentos del condicionalismo y la destrucción final de los impíos que sus contemporáneos adventistas formularon. A través de sus visiones, tuvo una comprensión temprana del asunto, luego con su visión escatológica que fue ampliándose desde 1858 hasta 1884, y finalmente con El conflicto de los siglos, validó las exposiciones bíblicas realizadas por estos escritores. Allí declaró de manera distintiva la naturaleza y tiempo del castigo y des- 
trucción realizada por Dios a los impenitentes. La Iglesia Adventista del Séptimo Día tiene mucho que aportar sobre estos temas frente a las múltiples opciones antropológicas y escatológicas prevalecientes actualmente. La enseñanza de la destrucción final presenta un sólido fundamento bíblico y a su vez, la validez profética sostenida y enseñada por la pionera Elena G. de White.

\section{Referencias}

ANDREWS, J. N. Annihilation. The Adventist Review and Sabbath Herald, v. 7, n. 21, p. 164, February 21, 1856.

ANDREWS, J. N. Destruction of the wicked. The Adventist Review and Sabbath Herald, v. 6, n. 11, p. 82-86, October 24, 1854.

ANDREWS, J. N. The judgment its events and their order. Oakland, CA: Pacific Press Publishing Company, 1890.

ANDREWS, J. N. Samuel and the Witch of Endor, or, The Sin of Witchcraft. Battle Creek, MI: Seventh-Day Adventist Publishing Association, 1889.

ANDREWS, J. N. The Three Messages of Revelation 14:6-12. Oakland, CA: Pacific Press Publishing Company, 1876.

ANDREWS, J. N. The Three Messages of Rev. xiv, 6-12. Review and Herald, v. 6, n. 24, p. 185-187, March 6, 1855.

ASOCIACIÓN Ministerial de la Asociación General de los Adventistas del Séptimo Día. Creencias de los Adventistas del Séptimo Día. Buenos Aires: ACES, 2007.

BATES, J. The Opening Heavens. New Bedford, MA: Press of Benjamin Lindsey, 1846.

BATES, J. The Second Advent Way Marks and High Heaps or A Connected View of the Fulfilment of Prophecy by God's peculiar People from the year 1840 to 1847. New Bedford, MA: Press of Benjamin Lindsey, 1847.

BLISS, S. Memoirs of William Miller: A Lecturer on the Prophecies, and the Second Coming of Christ. Boston, MA: Joshua V. Himes, 1853.

BONDA, J. The One Purpose of God: An Answer to the Doctrine of Eternal Punishment. Grand Rapids, MI: W.B. Eerdmans, 1998.

BULL, M.; LOCKHART, K. Seeking a Sanctuary: Seventh-day Adventism and the American Dream. Bloomington, IN: Indiana University Press, 2007.

CANRIGHT, D. M. Origen of the Doctrine of the Immortality of the Soul and Eternal Misery. The Adventist Review and Sabbath Herald, v. 23, n. 2, p. 9-10, 8 December 1863.

CANRIGHT, D. M. A History of the Doctrine of the Soul. Battle Creek, MI: Steam Press, 1871.

CORNELL, M. E. Facts for the Times: Extracts from the Writings of Eminent Authors, Ancient and Modern. Battle Creek, MI: Published by Autor, 1858. 
CORRÊA, A. Development of Ellen G. White's View on Mortality of the Soul Between 1842 and 1884. Evangelio, v. 11, p. 29-56, 2008.

COTTRELL, R.F. Immortality- Spirit Rapping. The Adventist Review and Sabbath Herald, v. 4, n. 20, p. 56-57, November 22, 1853.

DATE, C. M.; HIGHFIEL, R. (Eds). A Consuming Passion. Eugene, OR: Pickwick Publications, 2015.

DATE, C. M.; STUMP, G. G.; ANDERSON, J. W. (Eds). Rethinking Hell: Readings in Evangelical Conditionalism. Eugene, OR: Cascade Books, 2014.

EDWARDS, J. The Eternity of Hell Torments. Disponible en: <http://www.biblebb.com/files/ edwards/eternity.htm > Accedido en: 9 de septiembre 2019.

FROOM, L. R. The Conditionalist Faith of Our Fathers. Review and Herald, Washington D. C., v. 2. 1965.

FUDGE, E. The Fire That Consumes: A Biblical and Historical Study of the Doctrine of Final. 3. Ed. Punishment. Eugene, OR: Cascade Books, 2011.

HAYES, Z. J. The Purgatorial View. William V. Crockett (Ed.). In: Four Views on Hell. Grand Rapids, MI: Zondervan, 1996.

HALL, D. P. Man not immortal: The only shield against the seductions of modern spiritualism. The Adventist Review and Sabbath Herald, v. 6, n. 18, p. 136-139, 19 February, 1854a.

HALL, D. P. Man not immortal: The only shield against the seductions of modern spiritualism. The Adventist Review and Sabbath Herald, v. 6, n. 19, p. 145-147, 26 February, 1854b.

JONES, A. T. The Immortality of the Soul, Is it a Scriptural Doctrine? Oakland, CA: Pacific Press Publishing Association, 1890.

KNIGHT, G. R. Millennial Fever and the End of the World: A Study of Millerite Adventism. Boise, ID: Pacific Press Publishing Association, 1993

KNIGHT, G. R. Nuestra identidad. Doral, FL: APIA, 2007.

MACDONALD, G. The Evangelical Universalist. Eugene, OR: Cascade Books, 2012.

MILLER, W. “Letter from Mr. Miller”, The Midnight Cry!, v. 6, n. 19, p. 355, May 23, 1844. Disponible en: <http://bit.ly/3cjOBIj> Accedido en: 9 de septiembre 2019.

ROCHA, J. M. O tormento dos ímpios e o sofrimento de Cristo. Kerygma, v. 2 n. 2, p. 41-54, 2007.

LITCH, J. The Anti-Annihilationist. Philadelphia: J. Litch, 1844.

LOUGHBOROUGH, J. N. El gran movimiento adventista. Jasper, Oregon: Adventist Pioneer Library, 2015.

LOUGHBOROUGH, J. N. Examination of the Scripture Testimony Concerning Man's present condition and his Future Reward or Punishment. Rochester, NY: The Advent Review, 1855.

LOUGHBOROUGH, J. N. Immortality of the Soul. The Adventist Review and Sabbath Herald, v. 13, n. 12, p. 89-90, February 10, 1859. 
PAROSCHI, W. Death as Sleep: The (Mis)use of a Biblical Metaphor. Journal of the Adventist Theological Society, v. 28, n. 1, p. 26-44, 2017.

PINNOCK, C. The Conditional View. William Crockett (ed). In: Four Views on Hell. Grand Rapids, Michigan: Zondervan Publishing House, 1992.

POWYS, D. 'Hell': A Hard Look at a Hard Question: The Fate of the Unrighteous in New Testament Thought. Eugene, OR: Wipf and Stock, 2007.

STACKHOUSE JR., J. G. Terminal Punishment. In: Four Views on Hell. Preston Sprinkle (Ed). Grand Rapids, MI: Zondervan, 2016.

SCHWARZ, R. W.; GREENLEAF, F. Light bearers to the remnant. Florida: Pacific Press, 1979.

STORRS, G. An Enquiry: ¿Are the Souls of the Wicked Immortal? In Six sermons. Albany, N.Y., 1842.

STORRS, G. "An Inquiry: Are the Wicked Immortal?. The Bible Examiner, May 1843, p. 13.

STORRS, G. Bible Examiner. v 5, n. 7, July 1850. Disponbile en: <http://bit.ly/3cjOBIj> Accedido en: 9 de septiembre 2019.

STORRS, G. Intermediate State of the Dead, or, State from Death until the Resurrection. The Bible Examiner, 3 - 21, January 1844a.

STORRS, G. The Resurrection of the Dead. The Bible Examiner, p. 23-28, January de 1844b.

SMITH, U. A Declaration of the Fundamental Principles Taught and Practiced by the Seventhday Adventists. Battle Creek, MI: Steam Press, 1872.

SMITH, U. Annihilation., v. 7, n. 21, p. 163, February 21, 1856.

SMITH, U. Examination of the Scripture Testimony Concerning Man's present condition and his Future Reward or Punishment. Rochester, NY: The Advent Review, 1855.

SMITH, U. Here and Hereafter or Man in Life and Death. Washington, D.C.: Review and Herald Publishing Association, 1897.

SMITH, U. Immortality of the Soul. Review \& Herald. v. 13, n. 12, p. 89-90, February 10, 1859.

SMITH, U. Man's nature and destiny or, the State of the Dead. Oakland, CA: Pacific Press, 1884a.

SMITH, U. Progress of Truth and Error. The Adventist Review and Sabbath Herald, v. 8, n. 5, p. 36, May 15, 1856.

SMITH, U. Synopsis of the present truth: A brief exposition of the views of S.D. Adventists. Battle Creek, MI: Seventh Day Adventist Publishing Association, 1884.

SMITH, U. Visions a Test. The Adventist Review and Sabbath Herald, v. 19, n. 7, p. 52-53, January 14, 1862.

SMITH, U. Which? Mortal or Immortal? Or, an Inquiry into the Present Constitution and Future Condition of Man. Battle Creek, MI: Review and Herald, 1860.

SPALDING, A. W. Captains of the Host. First Volume of a History of Seventh-day Adventists Covering the years 1845-1900. Washington, D.C.: Review and Herald Publishing Association, 1949. 
SNOOK, B. F. The time of Rewards and Punishment. The Adventist Review and Sabbath Herald, v. 23, n. 5, p. 33-34, December 29, 1863.

TALBOTT, T. The Inescapable Love of God. Eugene, OR: Cascade Book, 2014.

TIMM, A. R. El santuario y los mensajes de los tres ángeles. Buenos Aires: ACES, 2018.

TRAVIS, S. H. Christ and the Judgement of God. Peabody, MA: Hendrickson Publisher, 2008.

WAGGONER, J. H. A Vindication of the Doctrine of the Resurrection of the Unjust. Battle Creek, MI: Steam Press, 1870.

WAGGONER, J. H. The Nature and Tendency of Modern Spiritualism. Battle Creek, MI: Steam Press, 1857.

WAGGONER, J. H. Dr. Randolph and Spiritualism. The Adventist Review and Sabbath Herald, v. 13, n. 7, p. 52-53, January 6, 1859.

WALLS, J. L. Hell and Purgatory. In: SPRINKLE, P. (Ed.). Four Views on Hell. Grand Rapids, Michigan: Zondervan, 2016.

WALLS, J. L. Purgatory: The Logic of Total Transformation. New York: Oxford University Press, 2012.

WALLS, J. L. Heaven, Hell and Purgatory: A Protestant View of the Cosmic Drama. Grand Rapids, MI: Brazos Press, 2015.

WHITE, E. G. Alza tus ojos. Mountain View, CA: Publicaciones Interamericanas, 1982.

WHITE, E. G. Cada día con Dios. Mountain View, CA: Publicaciones Interamericanas, 1979.

WHITE, E. G. Consejos sobre el régimen alimenticio. Buenos Aires: ACES, 1995.

WHITE, E. G. Consejos sobre la obra de la escuela sabática. Buenos Aires: ACES, 1992.

WHITE, E. G. Dear Brethren and Sisters. The Present Truth, 1 August 1849, p. 1-20.

WHITE, E. G. El deseado de todas las gentes. Buenos Aires: ACES, 2014.

WHITE, E. G. El conflicto de los siglos. Buenos Aires: ACES, 2015

WHITE, E. G. El discurso Maestro de Jesucristo. Buenos Aires: ACES, 2017a.

WHITE, E. G. El evangelismo. Buenos Aires: ACES, 2016a.

WHITE, E. G. Exaltad a Jesús. Buenos Aires: ACES, 1988a.

WHITE, E. G. Dios nos cuida. Buenos Aires: ACES, 1991.

WHITE, E. G. Hijos e hijas de Dios. Nampa, ID: Publicaciones Interamericanas, 1999.

WHITE, E. G. Joyas de los testimonios. Buenos Aires: ACES, 2016b. v.1.

WHITE, E. G. Joyas de los testimonios. Buenos Aires: ACES, 2016c. v. 2

WHITE, E. G. Manuscrito 75. 20 de septiembre de 1906. 
WHITE, E. G. Maranatha. El Señor viene. Buenos Aires, ACES: 1976.

WHITE, E. G. Notas biográficas de Elena de White. Buenos Aires: ACES, 2013.

WHITE, E. G. Life Sketches of Ellen G. White. Mountain View, CA: Pacific Press, 1915.

WHITE, E. G. Patriarcas y profetas. Buenos Aires: ACES, 1985.

WHITE, E. G. Phrenology, Psychology, Mesmerism, and Spritualism, The Adventist Review and Sabbath Herald, v. 19, n. 17, p. 94-95, March 25, 1862.

WHITE, E. G. Primeros escritos. Buenos Aires: ACES, 2017.

WHITE, E. G. Spiritual Gifts 1. Battle Creek, MI: James White, 1858.

WHITE, E. G. The Spirit of Prophecy 4. Battle Creek, MI: Steam Press, 1884.

WHITE, E. G. Supplement to the Christian Experience and Views of Ellen G. White. Rochester, NY: James White, 1854.

WHITE, E. G. The Great Controversy between Christ and Satan During the Christian Dispensation. Oakland, CA: Pacific Press, 1888.

WHITE, E. G. The Great Controversy between Christ and Satan: The Conflict of the Ages in the Christian Dispensation. Washington, DC: Review and Herald, 1911.

WHITE, E. G. Testimonies for the Church 1. Mountain View, CA: Pacific Press Publishing Association, 1885.

WHITE, E. G. Testimony for the Church [No. 1]. Battle Creek, MI: Advent Review Office, 1855.

WHITE, E. G. Testimonies for the Church 5. Mountain View, CA: Pacific Press Publishing Association, 1889.

WHITE, E. G. Testimonies for the Church 4. Boise, ID: Pacific Press, $1988 \mathrm{~b}$.

WHITE, E. G. Testimonios selectos 2. Buenos Aires: Casa Editora Sudamericana, 1927.

WHITE, E. G. Testimonios selectos 3. Buenos Aires: Casa Editora Sudamericana, 1934.

WHITE, E. G. Youth Instructor, November 3, 1908. Disponible en: <http://bit.ly/3ovVkBc $>$. Accedido en: 21 de Septiembre 2019.

WHITE, J. A Word to the Little Flock. Gorham, ME: Day-Down, 1847.

WHITE, J. Life Incidents. Battle Creek, MI: Steam Press, 1868.

WHITE, J. Sign of the Times. Review and Herald, v. 4, n. 8, p. 58-63, August 28, 1853. 